\title{
Planejamento para a Avaliação e Avaliação para o Replanejamento: Estudo de Caso com uma Sequência Didática sobre Saúde e Alimentação
}

\section{RESUMO}

Douglas William Cirino douglaswcirino@hotmail.com 000-0002-2273-9215 ral do $A B C$, Santo André, São Paulo, Brasil.

\section{Erik Flávio Vinturi} erik.vinturi@gmail.com 000-0002-7866-0434 Universidade Federal do ABC, Santo André, São Paulo, Brasil.

Vitor Andrade Nascimento vitor.andrade.1995@gmail.com 0000-0002-3999-7624 Universidade Federal do ABC, Santo André, São Paulo, Brasil.

João Paulo de Oliveira Xavier poliveiraxavier@gmail.com 0000-0003-4074-6627

Universidade Federal do ABC, Santo André, São Paulo, Brasil.

Monique Maia de Oliveira maia monique@hotmail.com maia monique@ $0000-0001-6755-0566$

Universidade Federal do ABC, Santo André, São Paulo, Brasil.

\section{Esaú Sirius}

esa sirius@hotmail.com

Universidade Federal do ABC, Santo Universidade Federal do

\section{Patrícia Vieira Antoniassi} pattypvieira@gmail.com 0000-0002-1416-1687 Universidade Federal do ABC, Santo André, São Paulo, Brasil.

Natalia Pirani Ghilardi Lopes natalia.lopes@ufabc.edu.br 0000-0001-6213-8871

Universidade Federal do ABC, Santo André, São Paulo, Brasil.
Planejar sequências didáticas é uma tarefa complexa e que demanda investimento de tempo. Neste artigo relatamos e refletimos sobre a utilização de diferentes formas de avaliação planejadas para uma sequência didática com o tema "Saúde e Alimentação". Observamos que muitos alunos se sentem desconfortáveis quando são submetidos a formas "não tradicionais" de avaliação, demonstrando insegurança em argumentar e expressar suas ideias, além de dificuldade em correlacionar informações. Além disso, é importante que o professor reveja continuamente seu planejamento em relação à avaliação, pois ao longo da aplicação da sequência didática observou-se a necessidade de adequação de aspectos inicialmente planejados. A sequência didática contribuiu para a formação inicial de licenciandos participantes do PIBID - UFABC, dentro de um contexto colaborativo e reflexivo.

PALAVRAS-CHAVE: Planejamento. Avaliação. Sequência Didática. PIBID. 


\section{INTRODUÇÃO}

Avaliar trata-se de um processo presente nas mais diversas esferas das relações interpessoais e deveria ser um processo corriqueiro, que acompanha a vida dos indivíduos desde seu nascimento. Entretanto, pouco se reflete sobre o ato de avaliar (CATANI e GALLEGO, 2009).

$\mathrm{Na}$ escola, muitas vezes os alunos associam a avaliação ao processo de "passar de ano" ou "receber boas notas" (CATANI e GALLEGO, 2009; JUSTINA e FERRAZ, 2009), ou seja, a motivação do aluno na escola é muitas vezes extrínseca (trabalhar em resposta a algo externo às suas tarefas, como a obtenção de recompensas externas, em geral, com a finalidade de atender solicitações ou pressões de outras pessoas) e não intrínseca (realizar determinada atividade pela própria causa, por considerá-la interessante, atraente ou geradora de satisfação) (NEVES e BORUCHOVITCH, 2004). Dessa forma, a avaliação acaba por perder seu real significado, qual seja, servir como reflexão do nível de qualidade do trabalho escolar tanto do professor quanto dos alunos (SANTOS e CANEN, 2014).

Adicionalmente, o processo de avaliação deve ocorrer de forma continuada, sendo pensado logo durante o planejamento das aulas (CATANI e GALLEGO, 2009), visando impulsionar o processo de ensino e aprendizagem, no qual professor e aluno verificam e analisam, num processo constante, o sentido dos métodos, explicações e ações em busca do conhecimento (JUSTINA e FERRAZ, 2009). Através da avaliação, o educador pode comparar os resultados que vão sendo obtidos no decorrer do trabalho com os objetivos propostos a fim de constatar progressos, dificuldades, e reorientar o trabalho para as correções necessárias (LIBANEO, 1994).

Atualmente, há uma grande dificuldade por parte do docente em identificar as possíveis barreiras que impedem a real apreensão do conhecimento por parte do aluno, que não significa apenas a memorização sistemática e pontual do conteúdo (JUSTINA e FERRAZ, 2009). Em função disso, é necessária a adoção de métodos variados de avaliação, que permitam não somente a mensuração das competências e habilidades dos alunos, mas também a eficácia das próprias ações didáticas (HOFFMAN, 2001).

Uma vez que o professor se sinta mais seguro quanto às dificuldades que encontrará no processo de ensino e aprendizagem em sala de aula, torna-se possível que ele pense mais objetivamente em planejar suas ações levando estas dificuldades em conta e, ainda, que pense no processo de avaliação mais adequado ao seu contexto e também o replanejamento de suas ações com base na análise dos resultados apresentados pelos alunos (AQUINO, 1997). Dessa forma, fica evidente a importância de se pensar na avaliação logo que se inicia um planejamento de ação em sala de aula, e a partir dela obter informações relevantes para a continuidade do processo de ensino e aprendizagem.

No presente artigo, relatamos e refletimos sobre os resultados obtidos por diferentes instrumentos de avaliação planejados para uma sequência didática construída de maneira colaborativa pelos integrantes do subprojeto de Biologia do PIBID - UFABC, destacando como os alunos podem ser continuamente avaliados, e como o professor pode ser crítico e reflexivo no momento do planejamento de suas aulas e avaliações. 
Durante as reuniões periódicas ocorridas no âmbito do subprojeto da área de biologia do Programa Institucional de Bolsas de Iniciação à Docência (PIBID) da Universidade Federal do $A B C$ (UFABC), uma sequência didática de seis aulas foi planejada, abrangendo as relações entre alimentação, saúde e meio ambiente, com base no trabalho de Almeida et al. (2013). O tema foi escolhido não só pela adequação ao planejamento escolar, mas também pela possibilidade de integrar diferentes assuntos das ciências biológicas, o que levaria à necessidade de integração de saberes dos bolsistas e alunos. Todas as aulas foram aplicadas em nove salas de primeiro ano do ensino médio de uma escola pública estadual da cidade de Santo André, no grande $A B C$. Ao longo do processo de construção do plano de aulas, o grupo discutiu e refletiu sobre os instrumentos de avaliação que seriam utilizados em cada aula, partindo de um conceito de avaliação investigativa (conforme JUSTINA e FERRAZ, 2009) e diversificada como no pluralismo metodológico (LABURU et al., 2003).

As seis aulas planejadas interagem entre si em um grande contexto, sendo que sua execução e métodos de avaliação foram tais como segue:

\section{Aula 1 - Simulação de compra}

Atividade de simulação de compras em um mercado, na qual uma série de imagens de alimentos foi disposta em prateleiras, com suas determinadas tabelas nutricionais e preços. A partir disso, grupos, com 4 alunos cada, deveriam simular a compra semanal de uma família, anotando em um formulário fornecido as suas escolhas. Ao final da aula, iniciou-se uma conversa com os grupos de alunos e cinco perguntas foram feitas para cada sala: 1) "Quais tipos de alimentos geram mais resíduos?"; 2) "Quais tipos de embalagens levam mais tempo para serem decompostas?"; 3) "Quais embalagens podem ser reutilizadas ou recicladas?"; 4) "Vocês compraram algo diferente do que os pais de vocês compram nas suas casas?"; 5) "Acham que a dieta escolhida está condizente com a prática de exercícios físicos de vocês?"

As três primeiras questões visavam avaliar as concepções prévias (avaliação diagnóstica) dos grupos sobre a relação entre alimentação e geração de resíduos. As demais questões visavam promover a reflexão dos alunos sobre seus hábitos alimentares. Para evitar a ideia de que as perguntas "valeriam nota" e estimular a conversa com os alunos sem que eles se preocupassem com o que seria "certo" ou "errado", não foi solicitada a entrega das respostas por escrito e não fizemos anotações durante a conversa, sendo que apenas buscamos identificar padrões gerais de respostas.

A partir da análise qualitativa dos formulários preenchidos pelos grupos e das respostas dadas às questões em sala, buscamos identificar padrões de consumo, bem como verificar se os alunos conseguiam estabelecer relações entre consumo, problemas de saúde, padrões culturais e geração de resíduos. 


\section{Aula 2 - Histórico dos padrões de alimentação}

Partindo de uma aula expositiva que apresentasse aos alunos a problemática das mudanças alimentares associadas aos padrões sociais, econômicos, culturais e biológicos ao longo de distintos períodos da história global, estabeleceu-se uma atividade rápida (para entrega) onde, em um curto parágrafo (de 5 a 10 linhas) os alunos tiveram de dissertar, individualmente, acerca do que eles definiriam como alimentação saudável e alimentação não-saudável. Buscou-se avaliar o entendimento dos estudantes e a capacidade de apreensão do conhecimento acerca das mudanças alimentares, sociais, culturais e biológicas, em um contexto histórico, a partir da correlação entre indicadores apresentados na aula expositiva intitulada "Linha do Tempo dos Padrões Alimentares", quais sejam: padrões de alimentação humana ao longo de sua história, índices globais de sobrepeso e obesidade ao longo das décadas de 70 e 90 , bem como problemas causados pela carência de nutrientes (anemia, desnutrição, entre outros). A partir da análise qualitativa dos textos produzidos pelos alunos foram definidas unidades de significado, as quais foram reunidas em categorias emergentes. Quantificou-se o número de respostas dos alunos dentro de cada categoria obtida.

Buscou-se com a avaliação desta aula estimar a capacidade dos estudantes em correlacionar as mudanças alimentares ao longo do tempo e a qualidade de vida das populações humanas.

\section{Aula 3 - Pirâmide alimentar e dietas}

Foram apresentados aos alunos, em uma aula expositiva, conceitos sobre os tipos de nutrientes contidos nos alimentos e suas importâncias, a pirâmide alimentar, a leitura de uma tabela nutricional e a importância de uma dieta balanceada para uma vida mais saudável. Em seguida, foi realizada uma atividade em grupo (os mesmos já definidos na aula 1) que consistiu na análise de um exemplo de uma dieta alimentar "milagrosa", que promete um rápido emagrecimento numa base altamente proteica e sem o consumo de qualquer fonte de carboidratos, e solicitou-se aos alunos a identificação de irregularidades, comparada a uma dieta ideal. Após a análise da dieta, os alunos deveriam responder a duas questões:

1. Quais grupos de alimentos, nessa dieta, estão faltando ou estão em menor quantidade quando comparada a uma dieta ideal?

2. Em sua opinião, vocês aconselhariam alguém a fazer essa dieta "milagrosa"? Por quê? $\mathrm{O}$ que poderia acontecer com essa pessoa depois de certo tempo seguindo esta dieta?

Na primeira questão, com caráter investigativo, baseado na interpretação da dieta com base altamente proteica, o objetivo era o grupo constatar a falta da ingestão de carboidratos e o alto consumo de proteína, e na segunda questão era saber sobre a posição do grupo frente a esses tipos de dietas e quais as consequências que elas poderiam causar, como falta de energia ou algum tipo de doença gerada pela má alimentação.

As respostas foram analisadas, agrupadas e quali-quantificadas de acordo com esperadas respostas dentro da categoria "falta de carboidratos" e, na segunda, 
"pode gerar doenças" ou "falta de energia". Outras categorias foram pósestabelecidas (FALCÃO e REGNIER, 2009).

Esperava-se com essa atividade que os alunos se posicionassem criticamente em relação a uma dieta "milagrosa", que, como outras desse tipo, prometia um rápido emagrecimento com a proibição de alguns grupos de alimentos, e identificassem os grupos de alimentos que estão em falta ou em menor quantidade quando comparada a uma dieta ideal. A avaliação, propositalmente, não pedia conceitos memorizados, mas sim exigia dos alunos que eles utilizassem os conceitos apresentados em sala contextualizados em uma situação cotidiana.

\section{Aula 4 - Alimentação e saúde ambiental}

Inicialmente aplicou-se uma aula expositiva-dialogada sobre os diferentes tipos de resíduos, seu descarte e a relação entre alimentação e geração de resíduos. O bolsista do PIBID na posição de docente levou à sala de aula um saco de lixo de 50 litros cheio de embalagens e restos alimentares que foram coletados do chão do pátio da escola e correspondiam aos resíduos gerados pelos alunos da sala de aula durante o período de um intervalo. Desta forma, iniciou-se o diálogo e a discussão de conceitos acerca do lixo e sua relação com a alimentação. Após a aula foram solicitadas duas atividades aos alunos: (1) uma pesquisa e (2) uma dissertação.

Para a pesquisa, foi fornecido a cada aluno um tipo de resíduo, o qual deveria ser pesquisado em casa, com prazo de uma semana, em relação às principais características, tais como classificação, origem de geração e destinação final.

A pesquisa para casa teve como principal objetivo a verificação da competência do aluno em filtrar informações, afinal a quantia de informações disponível hoje é bastante variada e circula muito rápido, sendo essencial que o aluno consiga agir de forma investigativa (MUNFORD e LIMA, 2007) utilizando o desenvolvimento de sua autonomia para buscar respostas sobre determinado tema, promovendo a dúvida e o questionamento do aluno e a capacidade de selecionar a informação a ser utilizada. $O$ aluno que apresentou as informações atendendo aos itens solicitados (Tabela 1 ) atingiu o resultado esperado e obteve a nota máxima para a atividade (nota 1). Notas intermediárias foram atribuídas a alunos que não atenderam a solicitação da pesquisa, ou colocaram informações demasiadas. Nota mínima foi atribuída a plágios de internet (cópia integral de textos) e ao não atendimento da proposta de pesquisa, apresentando informações não solicitadas 
Item a ser pesquisado

Origem do Resíduo

Classificação

Descarte Final

Adequado

Riscos à Saúde

\section{Descrição}

O aluno deveria pesquisar onde se origina tal resíduo, ex.: origem industrial, urbana, rural e as principais aplicações do produto antes de se tornar resíduo;

O aluno deveria indicar qual a classificação de risco ou origem do resíduo, conforme especificado em aula, por exemplo, classificação por periculosidade e/ou origem;

Com base na classificação e origem do resíduo o aluno deveria buscar informações de como descartar adequadamente o resíduo, como explicitado em aula, buscando na internet, por exemplo, formas de se descartar móveis ou eletrodomésticos;

Entendendo a origem, os usos e descarte, o aluno deveria explicitar sucintamente qual era o risco que tal resíduo poderia trazer ao meio ambiente ou à saúde humana caso descartado inadequadamente.

Já na dissertação, buscou-se avaliar a capacidade do aluno de argumentar sobre a relação entre geração de resíduos e riscos à saúde. Esperava-se que os alunos relacionassem a alimentação, levando em conta seus diferentes tipos, com as diferentes maneiras de se gerar resíduos e também a relação do meio ambiente com a saúde. Os textos produzidos foram analisados qualitativamente e foram categorizados em função da profundidade da argumentação (Tabela 2). 
Argumentação ausente ou Foram consideradas insuficientes as dissertações que não inadequada apresentavam um posicionamento crítico, nem argumentos ou pontos de vista que discutissem o problema proposto.

Argumentação presente, Argumentos relacionados à aula apresentada em relação à saúde porém insuficiente e geração de resíduos, mas com caráter estritamente ambiental (sem levar em conta a saúde alimentar), sem relações entre os temas

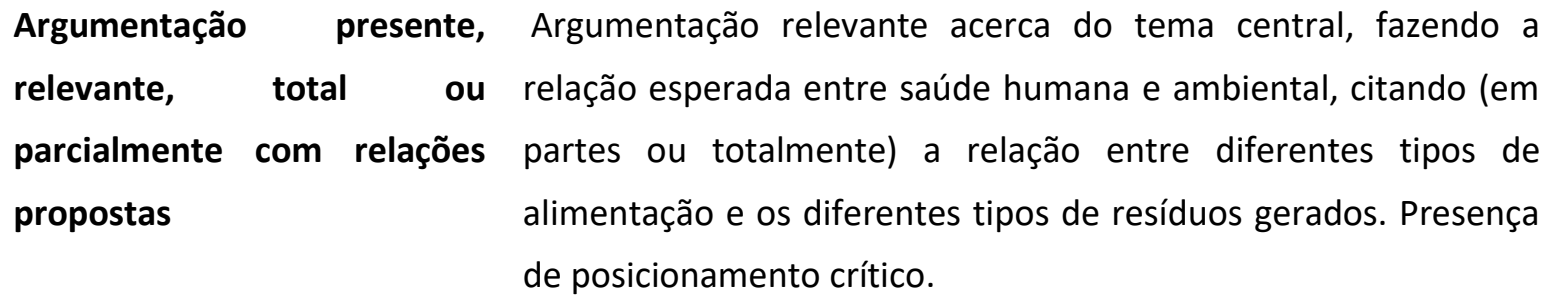

Aula 5 - Alimentação e saúde humana I

A avaliação dessa aula tinha como objetivo compreender se a aula expositiva foi um fator relevante para que os alunos mudassem suas concepções prévias acerca do tema abordado. Segundo GRAVINA E BUCHWEITZ (1994) "as concepções prévias (também chamadas de concepções alternativas) são concepções apresentadas pelos estudantes que são diferentes das concepções aceitas pela comunidade científica".

No início da aula, pediu-se aos alunos que respondessem três perguntas:

1.É melhor comer muito ou comer pouco? Por quê?

2.0 colesterol é bom ou ruim? Explique.

3.Comer muitos doces causa diabetes? Explique.

Após os alunos terem respondido, foi dada uma aula expositiva que tinha como tema "Alimentação e Doenças". Os conteúdos abordados foram: a importância de uma dieta equilibrada; o que é colesterol e as diferenças entre o colesterol "bom" e o colesterol "ruim", assim como sua relação com a obesidade e as doenças cardiovasculares; o que é diabetes, quais seus tipos e o que é a predisposição genética. Depois da aula, pediu-se novamente aos alunos que respondessem as mesmas três perguntas do início da aula e entregassem para o professor.

Realizou-se uma análise qualitativa das respostas dos alunos, comparando as respostas que os alunos deram antes da aula expositiva (concepções prévias) com 
as respostas dadas depois da aula expositiva, com o objetivo de observar se houve alguma alteração conceitual (SCHNETZLER, 1992). Essa metodologia também permitiu a realização de uma autoavaliação da aula expositiva aplicada (RÉGNIER, 2002).

\section{Aula 6 - Alimentação e saúde humana II}

Esta aula teórica e expositiva teve como enfoque as variáveis utilizadas para se diagnosticar problemas de saúde relacionados a uma alimentação e modo de vida pouco saudáveis. Além do Índice de Massa Corporal (IMC), exploraram-se variáveis como Frequência Cardíaca, tipos de colesterol e contagens de células sanguíneas.

Como método de avaliação, envelopes com informações previamente preparadas sobre pacientes hipotéticos foram entregues aos alunos, contendo informações típicas referentes a saúde destes, a saber: (i) idade, (ii) peso, (iii) altura, (iv) frequência cardíaca, (v) contagem de células do sangue e (vi) níveis de colesterol. Estes pacientes apresentavam variações nos valores destes parâmetros, as quais indicavam algum problema crônico em sua saúde relacionado a distúrbios alimentares. Havia ainda um paciente saudável e um paciente que, apesar de apresentar sobrepeso, trazia todos os outros valores dentro do aceitável em relação aos valores de referência. Com isso, esperava-se que os alunos fossem capazes de perceber que boa forma e saúde estão relacionados de maneira complexa e indireta.

Foi solicitado aos alunos que se reunissem em grupos de até quatro participantes e produzissem um "laudo" (para ser entregue ao final da aula) indicando a situação do paciente a partir da comparação dos valores de cada parâmetro com valores de referência fornecidos. Enquanto muitos dos valores de referência eram fornecidos diretamente, alguns deveriam ser calculados utilizando a idade, o peso e a altura do paciente como variáveis, a saber: a Frequências Cardíaca Máxima (FCM - calculada subtraindo-se a idade do paciente de 220, ou seja, um paciente com 30 anos teria FCM de 190) e o Índice de Massa Corporal (IMC - calculada dividindo-se o peso, em quilogramas, pela altura, em metros, ao quadrado). Esperava-se também que os alunos utilizassem regras de proporção para definir porcentagens da Frequência Cardíaca Máxima em que o corpo perde calorias, as chamadas faixas de treino (entre $65 \%$ e $85 \%$ da FCM).

Esta atividade teve como objetivo incentivar o espírito investigativo nos alunos, fomentando a recapitulação e reconstrução dos conhecimentos apreendidos durante a aula, contextualizando estes conceitos e permitindo o diálogo entre várias formas de conhecimento (AZEVEDO, 2004). A capacidade de reconhecer padrões e organizar informações (BRASIL, 2009) também foi uma competência avaliada, já que era necessária ao cumprimento da tarefa.

Os alunos receberam notas de 0 a 1 para a atividade. Nesta avaliação deu-se um peso maior para a discussão dos dados (máximo de 0,7 ) do que para os cálculos de IMC e de FCM (pontuações de 0,2 e 0,1 respectivamente).

Planejou-se, a partir da análise dos laudos produzidos pelos alunos, avaliar a sua capacidade de interpretar os valores fornecidos à luz de sua significância biológica e pela construção de uma visão crítica sobre os dados. 


\section{Resultados e Discussão}

\section{Aula 1 - Simulação de compra}

A partir dos métodos avaliativos propostos nesta aula, foi possível observar padrões de comportamento entre os estudantes. No geral, observou-se a falta de senso crítico dos alunos para questões relacionadas à alimentação, como produção de resíduos, influências culturais sobre o modo de consumo, valores nutricionais dos alimentos e prática de exercícios físicos.

Quando indagados sobre o que pensavam a respeito da geração de resíduos na hora da compra, com as perguntas 1) "Quais tipos de alimentos geram mais resíduos?", 2) "Quais tipos de embalagens levam mais tempo para se decomporem?" e 3) "Quais embalagens podem ser reutilizadas ou recicladas?", as respostas foram unânimes: nenhum aluno, das 9 salas nas quais a atividade foi proposta, se mostrou preocupado com a produção de resíduos, como, por exemplo, para onde iriam as embalagens depois de descartadas, quais embalagens poderiam ser recicladas ou reutilizadas e quais levariam mais tempo para se decomporem, o que é preocupante. Suas atitudes refletem a sociedade de consumo rápido, prático e constante, com alimentos industrializados, de fácil ou nenhum preparo e despreocupação com o destino final dos resíduos gerados, que cresce exponencialmente com o padrão de vida consumista de seus habitantes e, devido ao descarte inadequado, causa problemas ambientais (MUCELIN E BELLINI, 2008) e de saúde pública.

Analisando os formulários entregues no início da atividade, percebeu-se que grande parte dos estudantes priorizou a compra de alimentos de preparo rápido, como pizzas de microondas, $x$-burgueres, nuggets de frango e panquecas. Ao serem questionados com a pergunta 4) "Vocês compraram algo diferente do que os pais de vocês compram nas suas casas?", os alunos que se manifestaram disseram que não compraram nada que não fosse comum na residência de ao menos uma ou duas pessoas do grupo, pelo menos. Isso indica, mais uma vez, que suas escolhas são reflexo da família e da sociedade na qual estão inseridos. Segundo o "Guia alimentar para a população brasileira" (BRASIL, 2014), há uma tendência de substituição de alimentos in natura ou minimamente processados de origem vegetal (arroz, feijão, mandioca, batata, legumes e verduras) e preparações culinárias à base desses alimentos por produtos industrializados prontos para consumo.

Porém, os alimentos de preparo rápido não foram os únicos. Em sua maioria, os alunos compraram alimentos típicos da cultura brasileira, como arroz, feijão e carnes, acompanhados de alguns artigos para saladas, como alface, tomate, cebola e cenoura, por exemplo. Como isso foi percebido no decorrer da aula, os alunos puderam discutir a respeito da influência da sociedade sobre a dieta, com a ajuda do professor.

Durante a aula, pudemos ouvir o seguinte comentário de um aluno: demonstra que além de eles não terem uma visão ampla sobre alimentação 
saudável e balanceada, a intenção da aula não era que eles comprassem alimentos específicos, e sim que comprassem o que estão habituados a comprar, para que pudéssemos discutir aspectos relevantes a respeito de suas escolhas. Aqui a avaliação surge como um item estanque dentro da sala de aula, pois os alunos estavam em geral mais preocupados em serem avaliados do que em aprender e participar da atividade de forma construtiva, evidenciando a motivação extrínseca (conforme NEVES e BORUCHOVITCH, 2004).

Não parece claro para os alunos, também, a relação do modo de consumo, gasto energético e problemas relacionados à saúde, como obesidade, desnutrição, diabetes e outras. Ao serem indagados sobre a prática de exercícios (pergunta 5), poucos alunos disseram ter práticas condizentes com sua alimentação, o que é bastante preocupante, pois indica que problemas de saúde relacionados direta ou indiretamente à alimentação continuarão a preocupar os brasileiros.

Os resultados obtidos a partir dos instrumentos avaliativos evidenciam que o movimento pela incorporação da contextualização CTSA (Ciência, Tecnologia, Sociedade e Ambiente) no ensino de ciências no ensino básico, que vem crescendo devido aos problemas com os quais a sociedade vem enfrentando, relacionados às mudanças ambientais, problemas de saúde pública e à desigualdade social, e com o questionamento sobre o papel da ciência e da tecnologia para a sociedade contemporânea (SANTOS, 2007) precisa ser incentivado.

\section{Aula 2 - Histórico dos padrões de alimentação}

Após a análise dos dados obtidos a partir da avaliação proposta em sala, foram estabelecidas as seguintes categorias relacionadas às concepções de "Alimentação Saudável" e "Alimentação Não-Saudável":

- Alimentação Balanceada (equilíbrio entre grupos alimentares distintos): a noção de que a quantidade bem distribuída entre os diferentes tipos de alimentos (grupos alimentares) assegura saúde sem a necessidade de privação de determinados alimentos;

- Transições Históricas: fatores sociais, culturais, familiares e evolutivos cooperaram para as mudanças em termos de alimentação em torno do globo;

- Atividade física como fator contribuinte à qualidade de vida, estando associada à alimentação;

- Otimização de hábitos alimentares associados à rotina: a concepção de que a alimentação ao longo do dia não deve ocorrer de forma randômica, mas sim respeitando uma ordem temporal de refeições com produtos necessários à manutenção de energia;

- Utilização de parâmetros conceituais de caráter teórico - "carboidrato"; "proteína"; "colesterol"; "glicose"; etc. - como argumentos às mudanças de hábito alimentar.

A categoria mais presente nas respostas foi aquela baseada na utilização de "colesterol"; "glicose"; etc. - como argumentos às mudanças de hábito alimentar (35\%), seguida daquela que se refere à alimentação balanceada utilizando o 
equilíbrio entre os distintos grupos alimentares (32\%) (Figura 1). Tal resultado pôde evidenciar o entendimento prévio dos estudantes acerca de nutrientes importantes à manutenção da saúde e bem estar, bem como a percepção de equilíbrio no consumo dos distintos grupos alimentares onde se encontram tais nutrientes.

Observou-se ainda que grande parte dos alunos incluiu em sua concepção de alimentação saudável não só equilíbrio entre grupos alimentares, mas também o equilíbrio entre alimentos de origem natural e alimentos de origem industrial, corroborando o que já havia sido observado na primeira aula em que os alunos demonstraram essa tendência ao consumo de alimentos industrializados. Isso de certa forma era esperado, uma vez que eles ainda não tinham assistido à aula sobre tipos de dietas (aula 3), alimentação e resíduos (aula 4) e relação entre alimentação e saúde (aula 5). Assim, nosso objetivo de avaliar não somente os alunos de acordo com seu conhecimento absoluto, mas também o processo de aprendizagem fez-se possível, evidenciado a importância do planejamento como fator contribuinte ao processo de avaliação (BOTH , 2005).

Observou-se, ainda, que alguns alunos foram capazes de notar que a alimentação humana tornou-se menos saudável ao longo do tempo (transições históricas - 7\%), tanto por fatores de desenvolvimento industrial como de mudanças de hábito. Os alunos avaliados, mesmo ao longo de indagações no decorrer da aula, descreveram a alimentação provinda estritamente de segmentos industriais como prejudicial à saúde, havendo a concepção de que a alimentação de maior valia à saúde seria aquela que partisse do pressuposto de "naturalidade". As questões levantadas por estes alunos referem-se à rotina de seus antepassados e as mudanças sociais e culturais as quais estes sofreram. Tomada então a realidade atual (dos estudantes avaliados), onde alimentos exclusivamente naturais são de difícil aquisição, emprega-se como ideal balancear alimentos de origem natural e industrial, levando em consideração os grupos alimentares e distinção entre estes (Figura 1).

Se considerado o paralelo traçado com a aula anterior, onde houve a atividade para simulação de compras, evidencia-se a noção de que os padrões familiares ditados pela cultura na qual as famílias se inserem permeiam o entendimento e o posicionamento desses alunos perante a questão levantada a respeito de "Alimentação Saudável" e "Alimentação Não-Saudável" (AKATU, 2004). 
FIGURA 1 - Porcentagem de ocorrência de respostas dentro das categorias estabelecidas na atividade referente à definição de "alimentação saudável" e "alimentação nãosaudável".

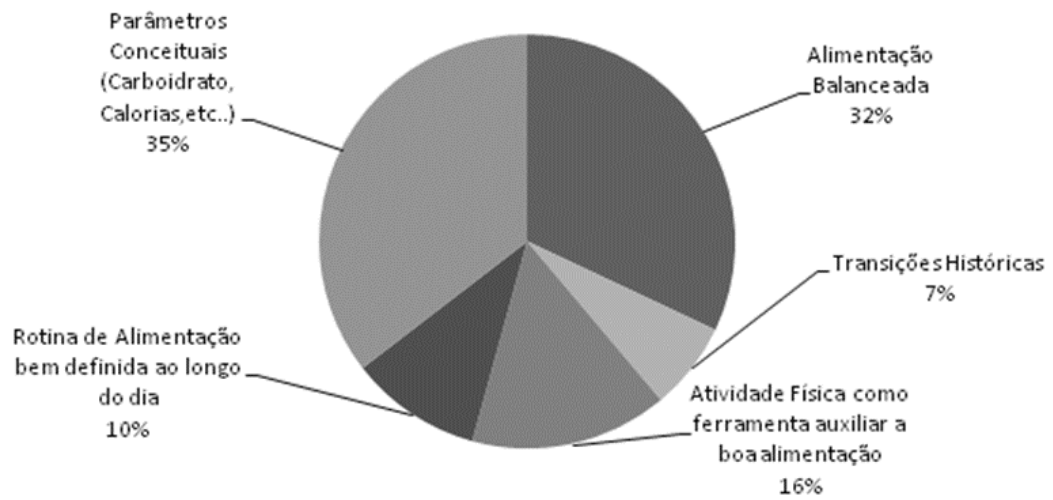

\section{Aula 3 - Pirâmide alimentar e dietas}

As duas questões aplicadas na atividade aos 64 grupos foram analisadas separadamente e agrupadas em categorias, de acordo com as respostas. $\mathrm{Na}$ primeira questão, perante a análise dos grupos de alimentos que faltavam na dieta "milagrosa" fornecida, dois grupos de alunos responderam que existia a falta de proteína, ao invés de carboidratos, na dieta, ou seja, estes grupos não conseguiram entender corretamente o conceito de proteína.

Já seis grupos de alunos, ao invés de responderem sobre os grupos alimentares ou tipos de alimento que faltavam ou estavam em menor quantidade na dieta (por exemplo: carboidratos, frutas e legumes) falaram sobre a falta de alimentos nas refeições diárias (falta de alimentos no almoço, jantar ou café da manhã) sem identificar os grupos alimentares. Podemos identificar nesta categoria a falta de interpretação de texto.

Dez grupos de alunos notaram a menor quantidade de alguns tipos de alimentos (frutas, verduras e legumes) na dieta, porém não identificaram a inexistência dos carboidratos, que são a base da pirâmide alimentar. Provavelmente, nesta categoria os alunos também não compreenderam o significado do conceito e que, por exemplo, os carboidratos estão presentes em pães, massas, etc.

Entretanto, 46 grupos identificaram a falta de carboidratos na dieta, o que era esperado como objetivo nesta questão. É notável o grande número de grupos que alcançaram o objetivo. Sendo assim, podemos agrupar as respostas da questão 1 em quatro categorias distintas, nas quais foram agrupadas as unidades de significado expressas pelos sujeitos pesquisados (Tabela 3). 
Tabela 3 - Respostas da questão “Quais grupos de alimentos, nessa dieta, estão faltando ou estão em menor quantidade quando comparada a uma dieta ideal?", agrupadas em categorias.

\begin{tabular}{ccc}
\hline Objetivo & Categorias das respostas & Número de respostas \\
\hline $\begin{array}{c}\text { Alcançado } \\
\text { Parcialmente } \\
\text { alcançado }\end{array}$ & Falta de carboidratos & 46 \\
Não alcançado & Notaram a falta de outros grupos, mas não \\
& carboidratos & 10 \\
& Falta de proteína & 2 \\
& Falta de alimento nas refeições (café da manhã, \\
& almoço e janta) & 6 \\
\hline
\end{tabular}

Na segunda questão não foi possível inferir se o entendimento dos conceitos passados foi ampliado ou não, pois as concepções prévias e alternativas não foram levantadas no início desta aula. Foi notado que os alunos já possuem algum conhecimento prévio sobre dietas "milagrosas" de revistas, pois concepções alternativas foram identificadas nas respostas pela utilização de termos como: "efeito sanfona", "engordar novamente" e "engordar o dobro" que não foram termos citados durante a aula.

Nas respostas analisadas da questão 2 também foram notados certos padrões, tendo sido identificadas seis categorias nas quais as unidades de significado foram agrupadas (Tabela 4).

Vinte e dois grupos responderam que não indicariam a dieta por não conter todos os nutrientes necessários para o corpo e quatro grupos não indicariam pois acham necessária a prática de exercícios físicos paralelamente. Contudo, 24 grupos não indicariam o seguimento de dietas milagrosas por poderem prejudicar a saúde e gerar algum tipo de doença. Já seis grupos visam a necessidade do acompanhamento de um nutricionista para o seguimento de uma dieta.

Esses grupos anteriores, que foram a grande maioria, atingiram o objetivo esperado pois justificaram sua negação a respeito do seguimento desses tipos de dietas com respostas dentro do esperado e que foram pontos levantados durante a aula.

Entretanto, cinco grupos atingiram parcialmente o objetivo pois não indicariam dietas "milagrosas" mas não sabiam justificar muito bem. Já três grupos indicariam o seguimento de dietas "milagrosas" não alcançando o objetivo esperado. Talvez os integrantes desses grupos não tenham prestado atenção durante a aula por isso não conseguiram desenvolver a atividade dentro do esperado. 
Tabela 4 - Respostas da questão “Em sua opinião, vocês aconselhariam alguém a fazer essa dieta "milagrosa"? Por quê? O que poderia acontecer com essa pessoa depois de certo tempo seguindo esta dieta?", agrupadas em categorias.

\section{Objetivo}

Faltam nutrientes em comparação a uma dieta

ideal

\section{Categorias das respostas}

Número de

respostas

\section{2}

4

Necessidade de exercícios físicos
Parcialmente

alcançado

Não alcançado

(1)

(1)

(1)

24

6

Consultar um nutricionista

5
Sabem que não faz bem, mas não sabem

justificar

24
6
5

Concordam com dietas milagrosas

Foi interessante notar que aqueles que acertaram a primeira questão não necessariamente acertaram a segunda, talvez por serem questões que requerem habilidades diferentes, sendo que uma exige a memorização de informações e a outra está relacionada à vivência, bem como à argumentação com base em conhecimentos científicos ou empíricos. Mas, no geral, o objetivo da aula foi atingido levando em consideração que é quase impossível atingir $100 \%$ dos alunos por conta de sua heterogeneidade.

O planejamento foi repensado durante e após a regência desta aula e verificou-se que algumas mudanças podem auxiliar no aprimoramento da aula, como por exemplo: 1) aplicação de uma avaliação inicial diagnóstica a fim de levantar e analisar concepções alternativas. De acordo com Ausubel et al. (1980), a aprendizagem poderá ser significativa se houver um avanço em busca por uma resposta a partir dos conhecimentos prévios e consigam orientar o estudo para compreender melhor determinada situação-problema. 2) o estímulo para que os alunos contem suas experiências pessoais, hábitos e atitudes; 3) uso de vocabulário mais adequado em algumas situações para facilitar o aprendizado; 4) separação da questão 2 em duas ou mais perguntas, pois alguns grupos não terminaram de respondê-la já que foram feitas 3 perguntas numa mesma questão.

\section{Aula 4 - Alimentação e saúde ambiental}

Em relação à pesquisa efetuada em casa pelos alunos sobre resíduos sólidos e saúde, observa-se que um grande número (aproximadamente $46 \%$ ) atingiu o resultado esperado, apresentando na pesquisa a totalidade, ou quase, dos itens propostos (Figura 2 - notas de 0,8 a 1 ). 
No caso das pesquisas consideradas inadequadas, observou-se que muitos alunos pesquisaram palavras-chave na internet e copiaram textos quase que integralmente, sem se preocupar com a organização e lógica das informações neles contidas.

FIGURA 2 - Distribuição de notas atribuídas às pesquisas sobre resíduos sólidos e saúde.

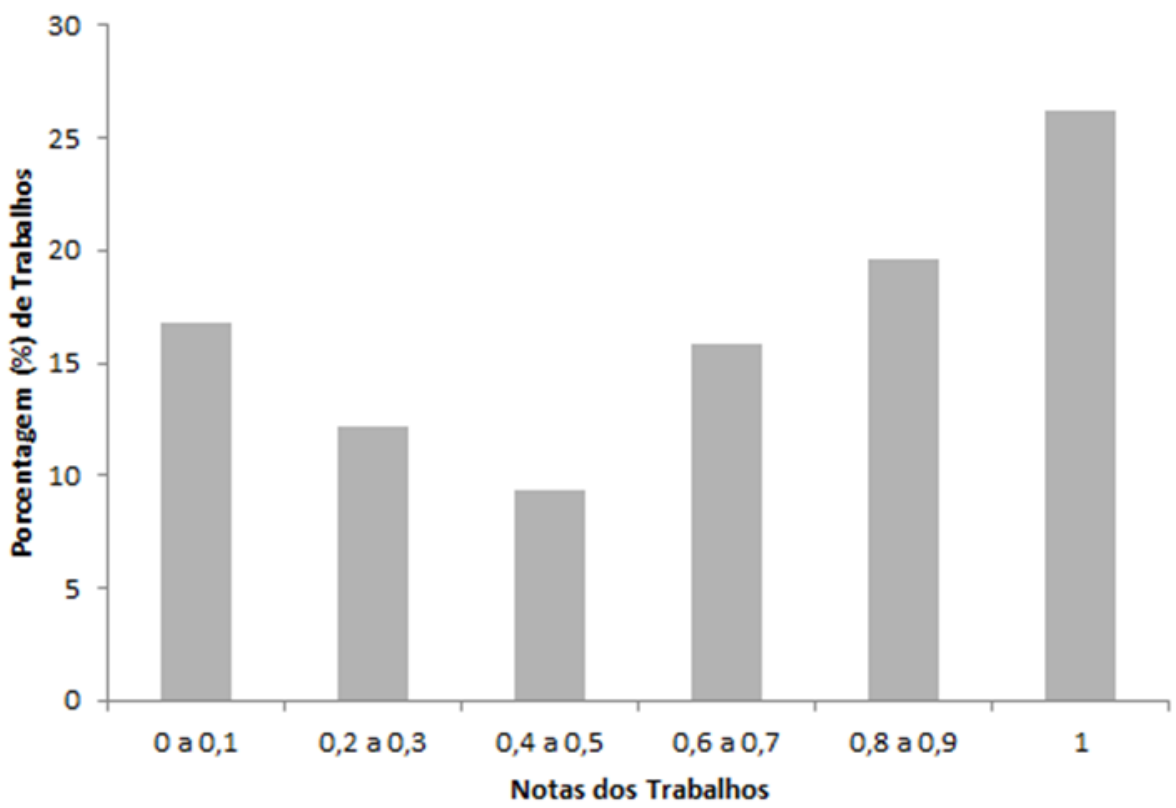

Notadamente, um número alto de alunos (29\%) não entendeu o propósito da atividade (Figura 2 - notas de 0 a 0,3). Para exemplificar, um aluno que deveria indicar a origem e forma de descarte de uma lata de alumínio colocou tal informação na pesquisa:

“ORIGEM: Tudo começou em 1940, os produtores de latas começaram a tentar adaptá-las para bebidas [...]

CLASSIFICAÇÃO: Nem todas as latas são guardadas em bom estado, em particular as mais antigas. Algumas podem ter amassados ou ferrugens [...]"

Outro aluno, que deveria pesquisar sobre origem e descarte de geladeiras velhas, em sua pesquisa explicitou a história da origem da geladeira e a classificação enquanto objeto decorativo. Foi recorrente tal confusão, sendo que quando questionados a pesquisar sobre a origem de um resíduo sólido, os alunos constantemente pesquisavam a história do produto como, por exemplo, a história das latas de alumínio, ou do papel, pneus, móveis, etc.

Do ponto de vista avaliativo, notamos que os alunos muitas vezes não têm seu senso crítico desenvolvido, e confundem colocar grande número de informações com colocar informações de qualidade e relevância.

Por outro lado, como esperado e como indicado na curva de distribuição de notas, muitos trabalhos tiveram resultados positivos, e também intermediários ( $25 \%$ - notas de 0,4 a 0,7$)$, e os alunos realizaram a pesquisa de forma a buscar 
informações para resolução do problema proposto: os diferentes tipos de lixo, suas formas de descarte e seus riscos. Tal processo avaliativo fez-se importante na medida em que os alunos eram sujeitos no processo de pesquisa da questãoproblema proposta a eles, a qual era inserida em seu cotidiano, o que vai ao encontro do Ensino por Investigação (AZEVEDO, 2004) dentro de uma abordagem CTSA (SANTOS, 2007) visando a Alfabetização Científica (SASSERON e CARVALHO, 2008).

$\mathrm{Na}$ dissertação, notamos novamente a necessidade de desenvolver o pensamento crítico em alguns alunos, sendo que muitas dissertações $(47,5 \%)$ não possuíam argumentação ou a correlação esperada e proposta pelo tema, porém os resultados se apresentaram positivos com relação ao número de alunos que atingiu o desempenho previamente esperado. Das 112 dissertações dos alunos de nove salas do primeiro ano do ensino médio, mais da metade $(52,5 \%)$ apresentou boa argumentação, relacionando os assuntos propostos (Figura 3 - argumentação presente e relevante), $32 \%$ não apresentavam a conexão entre os temas claramente, porém os abordavam ao longo do texto (Figura 3 - argumentação insuficiente) e 15\% não apresentavam argumentação (Figura 3 - argumentação ausente).

A argumentação é imprescindível para qualquer sujeito, nos vários campos de saberes e na vida cotidiana de um modo geral (LEMES, 2013). Segundo Pacífico (2002), a prática pedagógica predominante, pautada na paráfrase e repetição de sentidos e modelos, pode dificultar o aprendizado da argumentação. Consideramos que o exercício da argumentação deve estar presente nas mais diferentes disciplinas e buscamos trabalhar essa habilidade nesta aula.

FIGURA 3 - Distribuição de categorias de argumentação apresentadas nas dissertações sobre resíduos sólidos e saúde.

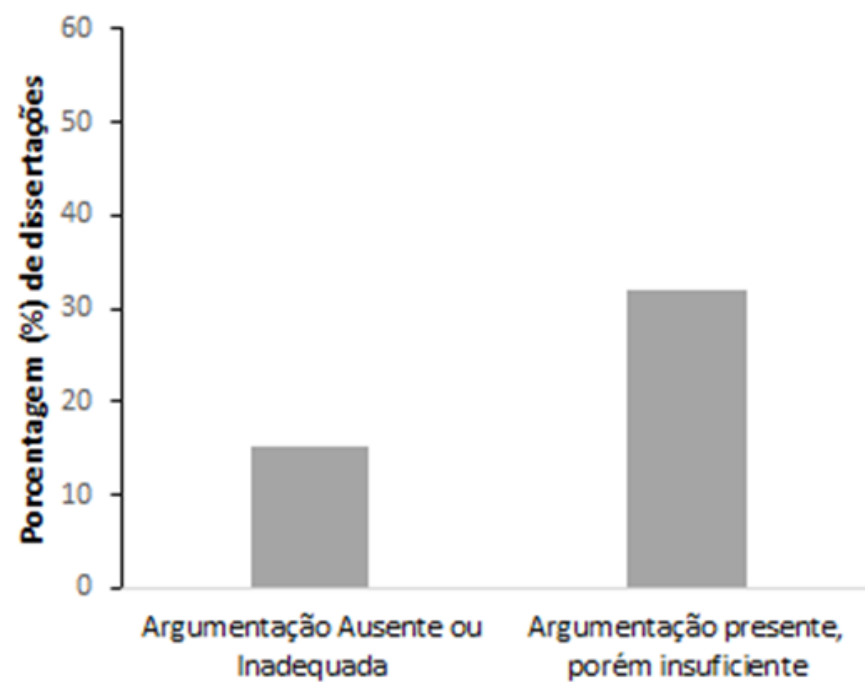

Categorias de argumentação

\author{
Argumentação presente, \\ relavante, total ou \\ parcialmente com relações \\ propostas
}


Pela avaliação feita das dissertações, poderíamos ter como resultado que a grande maioria dos alunos produziram o proposto, porém dentro da última categoria estão inseridos principalmente alunos que argumentaram muito bem sobre o tema, porém não delinearam também a interação entre a saúde alimentar e a geração de resíduos dos diferentes tipos de alimentação (saudável x nãosaudável).

Desta forma, por uma adequação didática, foram atribuídos à categoria máxima tanto os alunos que fizeram a inter-relação perfeitamente, quanto aqueles que chegaram próximos aos resultados esperados, argumentando adequadamente, porém relacionando parcialmente (ou superficialmente) as diferentes formas de se alimentar e os diferentes tipos de resíduos.

Como exemplo, temos o seguinte trecho de dissertação:

[...] Isso resulta numa sociedade cada vez menos saudável e mais consumista, que produz lixo descontrolável e não se dedica ao descarte correto [...]

No excerto acima, o aluno argumenta sobre a produção de lixo relacionandoa com o consumismo, colocando a sociedade num contexto ambiental e falando do descarte correto (ciência e tecnologia), numa perspectiva CTSA (SANTOS, 2007; MARCONDES et al., 2009), atingindo os objetivos iniciais da proposta da atividade. Tal dissertação foi colocada na categoria "Argumentação presente, relevante, total ou parcialmente com as relações propostas" e obteve uma nota 0,9 numa escala de 0 a 1.0 aluno faz algumas inter-relações entre os temas, mas não abordou a alimentação em seu contexto.

Já no seguinte trecho "[...] devemos tentar diminuir este lixo, comendo menos comidas industrializadas (que produzem bem mais lixo por conta das embalagens), reciclando o que for possível e reutilizando os materiais que pudermos [...]", identificamos diretamente a relação entre a alimentação e a geração de resíduos e seu posicionamento de forma crítica, abordando formas de descarte (reciclagem) e reaproveitamento de materiais, indo ao encontro da relação proposta e da discussão de saúde humana e ambiental.

Neste trecho, podemos dizer que encontramos o nível 2 de argumentação de Barroso (2007), no qual o indivíduo posiciona-se frente ao tema, coordenando e articulando mais de um argumento na justificativa.

Em outras dissertações, como no trecho a seguir, foi recorrente a percepção de que alguns alunos encontram-se em um nível pré-argumentativo (COIRIER e GOLDER, 1993), pois não argumentam de forma satisfatória e não abordam o tema de forma crítica ou fogem do solicitado apenas repetindo informações:

\footnotetext{
No mundo poucos sabem o que fazer com o lixo em geral [...]. Também não sabem a importância de jogar o lixo em seu respectivo lugar.

Existem vários lixões pelo mundo, mas isso acaba sendo um problema por ser exposto a todos[...]
}

A maioria das dissertações foi alocada na categoria de argumentação presente e relevante (Figura 3 ), apesar de nem todas essas dissertações terem sido baseadas no tema saúde alimentar, apenas citando o tema, e muitas vezes não terem 
abordado a questão da alimentação como produtora de resíduos. Entretanto, nota-se que os alunos têm um pensamento crítico sobre diversos aspectos relacionados ao lixo, sendo que o professor, ao avaliá-los, tem que ser capaz de reconhecer o desenvolvimento de tais capacidades nos alunos e não somente o entendimento total ou menção exata do que foi solicitado. Numa perspectiva de estilos de aprendizagem (FELDER e SILVERMAN, 1988), devemos ter a percepção da particularidade de aprendizado de cada aluno, entendendo que a apropriação do conhecimento e sua expressão (aqui, no caso, pela escrita) ocorrem de maneira distinta para os diferentes alunos.

Nesse aspecto, cabe ao professor refletir sobre tais práticas (PIMENTA, 2002), e isso é parte do processo avaliativo, no contexto da autoavaliação. Para esta aula, após passado o processo de aplicação e coleta de dados, o grupo notou que a aula 4 talvez fosse melhor aproveitada se tivesse sido aplicada como aula 3, para emendar o contexto histórico do consumismo e da alimentação da aula $2 \mathrm{com}$ a geração de resíduos que vem acompanhada com as novas formas de se alimentar pós revolução industrial.

\section{Aula 5 - Alimentação e saúde humana I}

Foram avaliadas três questões antes da aula expositiva e depois da aula expositiva. Na primeira questão "É melhor comer muito ou comer pouco?", era esperado que os alunos tivessem alguma noção de se alimentar corretamente, em quantidades necessárias, conhecendo o que é uma dieta equilibrada e isso fosse já apresentado nas concepções prévias dos estudantes, pois esse conteúdo já tinha sido abordado em aula anterior (Aula 3). No entanto, o padrão de resposta dos estudantes nas concepções prévias foi diferente do esperado. A maioria das respostas dos alunos foi "é melhor comer muito" e "é ruim comer pouco", sendo que o esperado era que os alunos respondessem que nenhuma das duas respostas era certa, que o melhor era ter uma dieta equilibrada, sem exageros nem restrições de quantidade. Esse padrão de resposta também foi observado quando os alunos responderam à questão novamente após a aula expositiva. É importante frisar que apesar da resposta não ser a esperada, a justificativa dos alunos estava certa, tanto quando os alunos responderam utilizando suas concepções prévias tanto depois da aula expositiva, como pode ser observado nas respostas dos alunos A1 e A2 abaixo:

\footnotetext{
A1: "Devemos comer muito, mas não podemos exagerar em comidas gordurosas e com sal."

(Antes da aula expositiva)

A2: "Comer pouco, com frutas, verduras e legumes e uma dieta saudável."

(Antes da aula expositiva)
}

Nas falas desses dois alunos é possível notar que eles compreendem a importância de uma dieta equilibrada, no entanto, foram compelidos a responder apenas "comer muito" ou "comer pouco". Acreditamos que o erro está na forma como a pergunta foi formulada, podendo ter parecido aos alunos uma pergunta binária, onde uma terceira resposta não seria aceitável. Provavelmente, os alunos tiveram receio de que a sua resposta fugisse da pergunta, por achar que não 
estariam certos. A autoavaliação da aula nesse caso permitiu a reflexão do professor, onde se concluiu que em uma próxima aula seria melhor optar por uma pergunta aberta em vez de uma pergunta fechada. "A principal vantagem da pergunta aberta é o fato de que o respondente não é influenciado pelo referencial do entrevistador na formulação da sua resposta e que a resposta mostra o que for mais saliente na percepção do respondente" (SHEATSLEY, 1983 apud GUNTHER, 1990). Após a aula expositiva, algumas das respostas para essa pergunta mudaram. Os alunos demonstraram compreender o que era uma dieta saudável:

A3:" Ter uma dieta saudável. Uma dieta saudável é aquela em que comemos os vários alimentos da pirâmide alimentar, em quantidades certas, ou seja, menos gorduras e doces e mais verduras, legumes, carboidratos e etc."

(Depois da aula expositiva)

A4:" Nem muito nem pouco. Tem que comer em quantidades ideais e comer mais verduras e legumes, igual na pirâmide e menos doces e gorduras."

(Depois da aula expositiva)

Na segunda pergunta antes da aula expositiva "O colesterol é bom ou é ruim? Explique", foi observado que os alunos sabem da existência de dois tipos de colesterol, no entanto não sabem diferenciá-los, como nos exemplos abaixo (alunos A5 e A6):

A5:" Existem os dois tipos de colesterol, o bom que faz bem para o corpo e o ruim que não."

(Antes da aula expositiva)

A6: "Os dois, por que tem os dois tipos."

(Antes da aula expositiva)

Após a aula expositiva, houve uma mudança nas concepções prévias dos alunos e ao responderem a mesma pergunta, muitos conseguiram diferenciar os dois tipos de colesterol, além de saber a terminologia LDL (Low density lipoprotein) e HDL (High density lipoprotein) e relacioná-las com o bem estar do corpo, apesar de algumas vezes confundirem os termos com seu respectivo significado.

A7: "Existem os dois tipos de colesterol: o LDL e o HDL, o LDL é o colesterol bom e ajuda a desentupir as artérias da gordura acumulada pelo HDL."

(Depois da aula expositiva)

A8: "O LDL é o colesterol que entope as artérias. Ele fica acumulado e é produzido no corpo a partir de uma má alimentação. O HDL consegue 'limpar' esse LDL que fica depositado nas artérias e é produzido no corpo a partir de uma boa alimentação."

(Depois da aula expositiva)

Nesse caso, a aula expositiva permitiu uma mudança do perfil conceitual dos alunos (MORTIMER, 1995), talvez sendo necessária apenas uma melhor apresentação dos termos LDL e HDL para que não ocorresse a troca dos seus 
respectivos significados. A mudança de perfil conceitual, segundo MORTIMER (1995):

Essa noção permite entender a evolução das ideias dos estudantes em sala de aula não como uma substituição de ideias alternativas por ideias científicas, mas como a evolução de um perfil de concepções, em que as novas ideias adquiridas no processo de ensino-aprendizagem passam a conviver com as ideias anteriores, sendo que cada uma delas pode ser empregada no contexto conveniente."

No entanto, para uma melhor análise do aprendizado dos alunos (aprendizagem significativa) seria necessário um tempo maior de pesquisa.

A última questão referia-se à relação da diabetes com a má alimentação e a predisposição genética: "Comer muitos doces causa diabetes?”. Quase todos os alunos responderam que comer muitos doces causa diabetes na questão antes da aula expositiva.

A9: "Sim, comer muito doce causa diabetes por que tem muito açúcar."

(Antes da aula expositiva)

Uma hipótese para explicar por que os alunos fazem essa relação é que como a diabetes tem relação com o aumento de açúcar no sangue, os alunos relacionam a doença com alimentos que contém açúcar.

Após a aula expositiva, os alunos responderam a mesma questão, e dessa vez as respostas estavam diferentes. Os alunos relacionavam o surgimento da diabetes com fatores genéticos e com a obesidade e o sedentarismo. Nesse caso, a aula expositiva também conseguiu mudar a concepção dos alunos sobre a relação doce e diabetes e os fatores que estão relacionados com o surgimento da doença.

A5: "A diabetes não é causada pelo consumo de doces, e sim pela obesidade.
Se uma pessoa tiver predisposição genética para ter diabetes e comer muitos
doces ela vai ficar obesa e provavelmente terá diabetes tipo II."

(Depois da aula expositiva)

Ao final dessa regência, foi realizada a autoavaliação da aula. Com a autoavalição foi possível refletir sobre a aula e o que poderia ser melhorado. $\mathrm{Na}$ questão 1 , perguntas abertas poderiam sanar o problema relacionado com o medo dos alunos de darem uma resposta que pareça fugir do enunciado. Segundo Sheatsley (1983 apud GUNTHER, 1990) a principal vantagem da pergunta aberta é a não-influência do referencial do professor na formulação da resposta do aluno. Na questão 2 e na questão 3, o uso de mapas conceituais durante a explicação poderia ter facilitado a compreensão dos alunos e promovido uma aprendizagem significativa (TAVARES, 2007), além de mitigado a troca de conceitos pelos alunos.

\section{Aula 6 - Alimentação e saúde humana II}

Houve no decorrer desta aula uma modificação dos parâmetros utilizados para avaliação já no momento em que as atividades estavam sendo recolhidas dos alunos em sala. Em um primeiro momento os alunos deveriam, a partir da frequência cardíaca máxima dos pacientes hipotéticos fornecidos na atividade (a 
qual eles deveriam calcular) e de regras de proporção simples, determinar frequências cardíacas de treino. A intenção era estabelecer um diálogo entre os diferentes saberes e mostrar a importância de um pensamento transversal e contextualizado na prática científica, ou seja, a partir de cálculos matemáticos os alunos poderiam entender como se determinam faixas de frequência cardíaca de treino. Contudo, verificou-se não só uma dificuldade dos alunos em relação à matemática, como também uma exacerbação da importância dela no contexto da avaliação, isto é, os alunos se demoravam mais e se esforçavam mais para fazer uso de uma matemática precária do que em discutir as variáveis e exibir os conhecimentos próprios das ciências biológicas. Isto se refletiu na nota, onde observa-se um pico de alunos com nota 0.2 , ou seja, que apenas se esforçaram no tempo disponível para calcular o IMC do paciente, mas que deixaram de lado as outras tarefas.

Neste ponto a matemática deixou de ser uma linguagem e uma forma de representação útil para se fazer inferências, e tornou-se um impeditivo para o pleno aproveitamento da atividade proposta, motivo pelo qual optou-se por simplificar esta parte da avaliação no curso da sequência didática. Em lugar da determinação das frequências cardíacas de treino através do uso de regras de proporção, apenas a frequência cardíaca máxima foi calculada e o índice de massa corporal. O restante das comparações manteve-se como um contraste entre valores medidos hipotéticos e valores de referência.

Um total de 37 trabalhos foi avaliado. Observou-se que houve um pico de trabalhos com nota 0,7 , em grande parte devido ao fato de os alunos não terem conseguido calcular o IMC e a FCM. Já $20 \%$ dos trabalhos obtiveram nota máxima (Figura 4).

FIGURA 4 - Distribuição das notas nos trabalhos entregues pelos alunos dos primeiros anos como atividade avaliativa da aula "Uma visita ao médico".

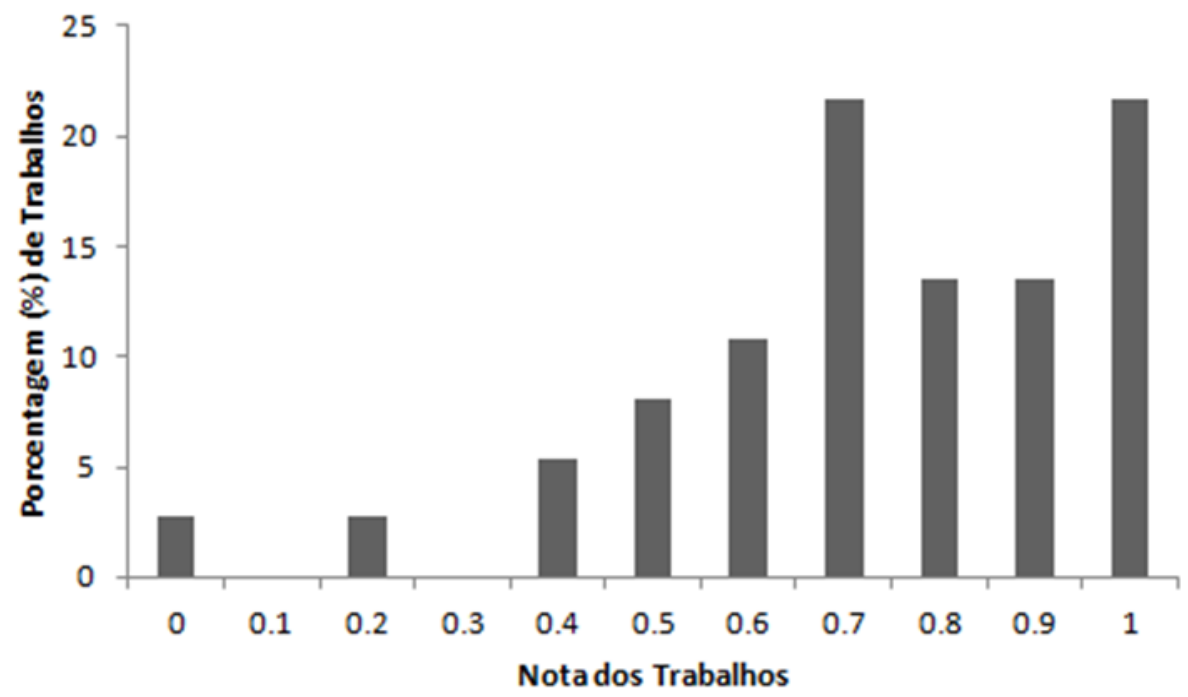

A avaliação não deve ser uma maneira de classificar os alunos, mas sim uma ferramenta de diálogo e construção de conhecimento (AQUINO, 1997) bem como de autoavaliação do professor (RÉGNIER, 2002). Desta forma, a modificação dos parâmetros solicitados no curso da sequência fez-se necessária não só permitindo uma coleta de dados de maior significado, isto é, que não avaliasse apenas a 
capacidade de realizar operações matemáticas, mas também restaurando um pouco dos objetivos iniciais da avaliação, que era o da discussão a respeito dos parâmetros presentes em exames médicos.

Além da falta de maestria mínima esperada com dados numéricos, o valor exacerbado que os alunos colocam sobre o uso da matemática foi o maior problema. A matematização do conhecimento científico é um problema frequente na filosofia das ciências, onde se pontua que, embora o uso de recursos matemáticos seja justificável e útil, eles tendem a ser supervalorizados e creditados inapropriadamente (DE LANGE, 1987). Esta sensação de validade científica inquestionável e de precisão refletiu na maneira com que os alunos trataram as variáveis, acabando no julgamento do educador por prejudicar o pensamento crítico acerca do exercício proposto. Adicionalmente, esse caráter infalível atribuído à matemática contrapõe-se ao método de avaliação investigativo pretendido.

Buscávamos avaliar os alunos por meio de indicadores qualitativos e quantitativos. Os indicadores quantitativos estariam implícitos na mera comparação de valores de referência com os valores do paciente hipotético, enquanto que o indicador qualitativo estaria na discussão destas comparações expressa por meio do diagnóstico. Nem sempre houve uma resposta crítica correlacionando os conhecimentos biológicos com os dados apresentados, como se esperava inicialmente. Isso se deve não só a uma dificuldade dos alunos em demonstrar essa integração do conhecimento, mas principalmente a dinâmica da sala de aula que muitas vezes desfavoreceu o fomento de discussões neste sentido. Embora a atividade proposta tivesse caráter investigativo e científico (JUSTINA \& FERRAZ, 2009; SASSERON \& CARVALHO, 2008) o uso de dados numéricos acabou causando a maior dificuldade e tornando-se o foco da atividade, consumindo ainda mais do tempo já escasso para discussões. A tentativa de uma avaliação que fizesse parte do processo de aprendizagem e fugisse ao caráter burocrático tradicional (AQUINO, 1997) foi em partes frustrada pela própria ânsia dos estudantes inseridos neste sistema em buscar a resposta correta e a maior nota, em lugar da troca de conhecimentos. Esta observação é interessante, pois aponta para a necessidade de uma transformação paulatina dos métodos de avaliação e ensino.

Como autoavaliação, verificou-se que a comparação entre as variáveis dos pacientes e os valores de referência poderia ter sido facilitada caso fosse fornecida uma tabela a ser preenchida pelos alunos que já organizasse a informação de maneira direta, ou seja, os dados de pressão arterial, colesterol e a contagem de células sanguíneas poderiam ser apresentados como linhas de uma tabela, cujas colunas refletiriam a situação desta variável. Entretanto, esperava-se avaliar justamente esta capacidade de reconhecimento de padrões e organização como competência importante aos alunos do ensino médio, e o bom cumprimento desta tarefa era prescindível para que a correlação entre conhecimentos fosse feita a contento. No decorrer das aulas, então, a indicação de patologias associadas e de uma dieta adequada a cada paciente acabou sendo delegada a um papel secundário por parte do aplicador. Esta mudança de cobrança e impossibilidade de cumprimento de todas as expectativas iniciais foi levada em conta no momento da atribuição de notas. 


\section{O processo avaliativo durante o processo de aprendizagem}

As seis aulas se desenvolveram com dois focos principais: a utilização de métodos avaliativos diversificados, contemplando o pluralismo metodológico de Laburu et al. (2003), através de um processo de ensino-aprendizagem com alfabetização científica, segundo Sasseron e Carvalho (2008), ambos seguindo uma abordagem de ensino CTSA (SANTOS, 2007). O grande objetivo do desenvolvimento de aulas com temas diversos, atendendo conteúdos escolares interdisciplinares, tornou possível um planejamento com o intuito de desenvolver nos alunos a percepção de que a escola não serve apenas para cobrar resultados, mas sim ensinar avaliando, permitindo a reflexão sobre o processo (BOTH, 2005). Buscamos evidenciar através das aulas que o objetivo da avaliação não é somente atribuir notas e classificar, mas sim desenvolver conhecimentos, habilidades e pensamentos através de instrumentos avaliativos (CHUERI, 2008), e que a avaliação não deve servir apenas para classificar o nível de conhecimento, mas também o processo de ensino gerido pelo professor de modo a permitir o replanejamento de suas aulas e de seus instrumentos avaliativos (HOFFMAN, 2001; GATTI, 2003). Assim, a avaliação passa a ser um processo continuado, durante o processo de planejamento (CATANI e GALLEGO, 2009).

\section{Conclusões e Considerações finais}

Pode-se notar que ao longo da sequência didática aplicaram-se diversificados métodos de avaliação (expressão oral dos alunos, respostas a questionários abertos, argumentação na forma de dissertação, aplicação de conceitos em situações hipotéticas, investigação). Todos foram utilizados em uma proposta de avaliação investigativa e a qualificação e quantificação dos resultados permitiram não só evidenciar o desempenho dos alunos em relação às metas estabelecidas no planejamento, mas também a própria avaliação da sequência proposta, o que permitiu a reflexão sobre a adequação dos métodos didáticos escolhidos para cada momento de ensino.

Em relação ao desempenho dos alunos nas atividades propostas, verificou-se que a grande maioria se sente insegura quando o instrumento avaliativo foge dos tradicionais métodos ainda bastante utilizados que priorizam a memorização de conceitos e não a sua compreensão, muito menos a correlação entre eles. Dessa forma, a dificuldade dos alunos em aplicar conceitos passados em sala em situações diferentes das apresentadas previamente pelo professor, bem como a dificuldade em correlacionar conceitos passados em diferentes aulas foi evidente. Segundo Grigoletto (1999), os livros didáticos (ou poderíamos pensar, no caso do presente trabalho, no "Caderno do Aluno do Estado de São Paulo") tem um papel importante neste problema, pois eles induzem os alunos a fazer a mesma leitura, a tirarem as mesmas conclusões e a reagirem de uma única forma às propostas apresentadas.

Outra questão importante foi em relação à forma como eram expostas as perguntas aos alunos. Muitas vezes, quando as perguntas apresentavam um caráter binário (“É melhor comer muito ou comer pouco?"), os alunos tinham receio de responder algo intermediário ou discordar das alternativas colocadas por 
cidadão cientificamente alfabetizado deve aprender a ter. Este problema se torna ainda mais grave quando verificamos a dificuldade dos alunos se expressarem em textos discursivo-argumentativos (principalmente na aula 4). O ensino da argumentação, muitas vezes, é delegado aos últimos anos escolares por ser considerado algo complexo e que depende do total domínio da língua pelo sujeito. Entretanto, isso pode configurar-se como uma subestimação da capacidade dos alunos em lidarem com um saber mais elaborado e, portanto, o direito ao "saber argumentar" estaria comprometido (LEMES, 2013).

Como aspecto positivo da sequência didática, observamos que grande parte dos alunos atingiu os objetivos esperados, indicando que o planejamento foi de encontro com diferentes perfis de aprendizagem (CERQUEIRA, 2006) e estilos cognitivos, mesmo sem termos realizado um levantamento prévio de tais estilos.

Em relação à avaliação da sequência didática (autoavaliação), observou-se que durante e após a aplicação de um plano de aula, é fundamental que o mesmo seja revisto e que ocorra o replanejamento. Isso ocorreu em alguns momentos, onde notávamos a necessidade de incluir ou retirar trechos inicialmente pensados, reformular questões que não ficaram claras aos alunos ou diminuir o grau de exigência inicialmente estabelecido, por este ser muito alto em relação ao que os alunos conseguiriam realizar no tempo de uma aula (no caso da aula 6). Não consideramos que isso seja um aspecto negativo da sequência didática, pelo contrário, já que consideramos que o planejamento e a avaliação são dois processos dinâmicos e mutáveis e que o professor, ao ter consciência disso, tornase capaz de efetivamente propor um ensino que traga algum aprendizado aos seus alunos.

A autoavaliação da aula pelo professor contribui para que o professor tenha um olhar crítico para a sua própria aula, refletindo sobre a sua prática docente. Segundo Hypolitto (1999), a reflexão leva o professor a repensar a sua prática, a sua metodologia e os seus objetivos: Quem é o aluno que está a minha frente, o que quer, qual a melhor linguagem para dialogar com ele? Por meio dessa reflexão, o professor pode verificar os erros e acertos e assim aprimorar sua prática. 
I// RBECT

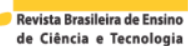

Página | 165 


\title{
Planning aiming at evaluation and evaluating for replanning: case study with a didactic sequence on Health and Feeding.
}

\begin{abstract}
Planning didactic sequences is a complex task, which needs investment of time. In the present study, we report and reflect about the use of different forms of evaluation planned for a teaching sequence with the theme "Health and Feeding". We observed that many students feel uncomfortable when they are subjected to "non-traditional" means of evaluation, showing insecurity to argue and express their ideas, and difficulty in correlating information. Furthermore, it is important that teachers continuously review their planning in relation to the evaluation methods, because during the implementation of the teaching sequence we observed the need to adapt some initially planned aspects. The instructional sequence contributed to the initial training of undergraduates that participate in PIBID UFABC within a collaborative and reflective context.
\end{abstract}

KEYWORDS: Planning. Evaluation. Didactic Sequence. PIBID. 


\section{Agradecimentos}

Agradecemos a CAPES, através do Programa Institucional de Bolsas de Iniciação à Docência (Pibid), pelo financiamento. Agradecemos a Comissão de Ética em Pesquisa da UFABC pelas contribuições ao texto dos Termos de Consentimento Livre e Esclarecido (CAAE 35417314.1.0000.5594).

\section{REFERÊNCIAS}

AKATU, Instituto - Caderno Temático: A Nutrição e o Consumo Consciente. Instituto Akatu, São Paulo ,2004.

ALMEIDA, E. M. P.; MONTANHA, S. M.; SANTANA, P. M. C.; SOARES, C. B. S. Educação Ambiental na Escola: Estudo da Relação Entre a Alimentação e a Produção de Resíduos. Revista Brasileira de Educação Ambiental. v. 8, n. 2, p. 131-149, 2013.

AQUINO, J.G. (org.). Erro e fracasso na escola: alternativas teóricas e práticas. São Paulo, Summus, 1997.

AUSUBEL, D. P., J. D. NOVAK, ; HANESIAN, H. Psicologia educacional. Rio de Janeiro: Editora Interamericana, 1980.

AZEVEDO, M.C.P.S. Ensino por investigação: problematizando as atividades em sala de aula. In: CARVALHO, A.M.P. (Org.). Ensino de Ciências: unindo a pesquisa e a prática. São Paulo: Cengage Learning Editores. cap. 2, p. 19-33, 2004.

BARROSO, T. O desenvolvimento do discurso argumentativo por crianças do ensino fundamental: articulação e coordenação de sequências argumentativas no texto de opinião. Veredas on line, 2007. p.101-117, 2007.

BOTH, I. J. Ensinar e Avaliar são de Domínio Público: resta saber se ensinar avaliando e avaliar ensinando também o são. Revista HISTEDBR On-line, Campinas, n.18, p.54-64, 2005.

BRASIL, Ministério da Educação. Competências e Habilidades: Ciências da Natureza e suas Tecnologias. In: BRASIL, Ministério da Educação. Matriz de 
BRASIL. Ministério da Saúde. Secretaria de Atenção à Saúde. Departamento de Atenção Básica. Guia alimentar para a população brasileira. 2. ed. Brasília: Ministério da Saúde, 156 p., 2014.

CATANI, D. B.; GALEGO, R. C. Avaliação. 1a Edição. São Paulo, Editora UNESP, 2009.

CERQUEIRA, T.C.S. O professor em sala de aula: reflexão sobre os estilos de aprendizagem e a escuta sensível. Psic - Revista de Psicologia da Vetor Editora, v. 7, n. 1, p. 29-38, 2006.

CHUERI, M. S. F. Concepções sobre avaliação escolar. Estudos em Avaliação Educacional, v.19, n.39, p.49-64, 2008.

COIRIER, P.; GOLDER, C. Writing argumentative text: a developmental study of the acquisition of supporting structures. European Journal of Psycology of Education, v. III, n. 2, p.169-181, 1993.

DE LANGE, J. Mathematics, Insight and Meaning. Utrecht: OW \&OC, 1987.

FALCÃO, J. T. R.; RÉGNIER, J. Sobre os métodos quantitativos na pesquisa em ciências humanas: riscos e benefícios para o pesquisador. Revista Brasileira de Estudos Pedagógicos, v. 81, n. 198, p. 229-243, 2000.

FELDER, R. M.; SILVERMAN, L. K. Learning and teaching styles in Engineering Education. Engineering Education, v. 7, n. 8, p. 674-681, 1988.

GATTI, B. A. O Professor e a Avaliação em Sala de Aula. Estudos em Avaliação Educacional, n. 27, p.97-114, 2003.

GRAVINA, M. H.; BUCHWEITZ, B. Mudanças nas Concepções Alternativas de Estudantes Relacionadas com Eletricidade. Revista Brasileira de Ensino de Física, v. 16, n.1-4, p. 110-119, 1994.

GRIGOLETTO, M. Leitura e funcionamento discursivo do livro didático. In: CORACINI, M.J. (Org.). Interpretação, autoria e legitimação do livro didático. Campinas: Pontes, 1999.

GUNTHER, JÚNIOR, J.L. H. Perguntas Abertas Versus Perguntas Fechadas: uma Comparação Empírica. Psic.: Teor. e Pesq., v. 6, n 2, p. 203-213,1990. 
HOFFMAN, J. Avaliar para promover: as setas do caminho. Porto Alegre: Mediação, 2001.

HYPOLLITO, D. O Professor como Profissional Reflexivo. Integração Ensino, Pesquisa, Extensão. Ano 5, n. 18, p. 204-205, 1999.

JUSTINA, L. A. D.; FERRAZ, D. F. A Prática Avaliativa no Contexto do Ensino de Biologia. In: CALDEIRA, A. M. A.; ARAUJO, E. S. N. N. Introdução à didática da Biologia. São Paulo, 1ạ edição, Editora Escrituras. p. 233-246, 2009.

LABURÚ, C. E.; ARRUDA, S. M.; NARDI, R. Pluralismo Metodológico no Ensino de Ciências, Ciência \& Educação, Brasília, v. 9, n. 2, p. 247-260, 2003.

LEMES, N. Argumentação, livro didático e discurso jornalístico: vozes que se cruzam na disputa pelo dizer e silenciar. 116f. Dissertação (Mestrado em Educação) - Faculdade de Filosofia, Ciências e Letras de Ribeirão Preto, Universidade de São Paulo, 2013.

LIBÂNEO, J. C. Didática. São Paulo: Cortez Editora, 1994.

MARCONDES, M. E. R; CARMO, M. P.; SUART, R. C.; SILVA, E. L.; SOUZA, F. L.; SANTOS JR, J. B.; AKAHOSHI, L. H. Materiais Instrucionais Numa Perspectiva CTSA: Uma Análise de Unidades Didáticas Produzidas por Professores em Química numa Formação Continuada. Investigação em Ensino de Ciências, v. 14, n. 2, p. 281-298, 2009.

MORTIMER, E.F. Conceptual change or conceptual profile change? Science \& Education, 4(3): 265-287, 1995.

MUCELIN, C.A., BELLINI, M. Lixo e impactos ambientais perceptíveis no ecossistema urbano. Rev. Sociedade \& Natureza, v. 20, n. 1, p. 111- 124, 2008.

MUNFORD, D.; LIMA, M.E.C.C.. Ensinar ciências por investigação: em quê estamos de acordo? Ensaio, n.1, v. 9, jul. 2007

NEVES, E. R. C.; BORUCHOVITCH, E. A motivação de alunos no contexto da progressão continuada. Revista Psicologia: Teoria e Pesquisa, v. 20, n. 1, p. 77-85, 2004.

PACÍFICO, S.M.R. Argumentação e autoria: o silenciamento do dizer.190f. Tese 
PIMENTA, S. G. Professor Reflexivo: Construindo uma Crítica. In: PIMENTA, S. G.; GHEDIN, E. (org.) Professor Reflexivo no Brasil. Editora Cortez, 4a edição. p. 1752. 2002.

RÉGNIER, J.C. A Auto-avaliação na Prática Pedagógica .Revista Diálogo Educacional, v. 3, n. 6, p. 1-16, 2002.

SANTOS, A.P.S.; CANEN, A. Avaliação Escolar Para a Aprendizagem: possibilidades e avanços na prática pedagógica. Meta: Avaliação, Rio de Janeiro, v. 6, n. 16, p. 53-70, 2014.

SANTOS, W. L. P. Contextualização no Ensino de Ciências por Meio de Temas CTS em Uma Perspectiva Crítica. Ciência \& Ensino, vol. 1, Número Especial, 2007.

SASSERON, L. H. \& CARVALHO, A. M. P. 2008. Almejando a Alfabetização Científica no Ensino Fundamental: A Proposição e a Procura de Indicadores de Processo. Investigação em Ensino de Ciências, v. 13, n. 3, p. 333-352, 2008.

SCHNETZLER, R.P. Construção do Conhecimento e Ensino de Ciências. Em Aberto, ano 11, n. 55, p. 17-22, 1992.

SHEATSLEY, P. B. Questionnaire construction and item writing. In: P. H. Rossi, J. D. Wright, \& A. B. Anderson (Orgs.). Handbook of survey research. Orlando, FL: Academic Press. p. 195-230, 1983.

TAVARES, R. Construindo Mapas Conceituais. Ciências \& Cognição, v, 12, p. 72-85, 2007.

Recebido: 03 mar. 2015

Aprovado: 02 fev. 2017.

DOI: $10.3895 /$ rbect.v9n3.2804

Como citar: CIRINO, D. W.; VINTURI, E. F.; NASCIMENTO, V. A.; et al. Planejamento para a Avaliação e

Avaliação para o Replanejamento: Estudo de Caso com uma Sequência Didática sobre Saúde e

Alimentação. Revista Brasileira de Ensino de Ciência e Tecnologia, v. 9, n. 3, 2016. Disponível em:

$<$ https://periodicos.utfpr.edu.br/rbect/article/view/2804>. Acesso em: xxx.

Correspondência:

Direito autoral: Este artigo está licenciado sob os termos da Licença Creative Commons-Atribuição 4.0 Internacional. 